\title{
Analiza wpływu warunków materiałowo technologicznych na własności połączeń elementów z powłokami na bazie cynku
}

\section{Influence analysis of technological and material conditions on properties of zinc coated steel joints}

\section{Streszczenie}

Przedstawiono trudności związane z łączeniem elementów ocynkowanych oraz omówiono wpływ cynku na przebieg procesu spawania i lutospawania elektrodą topliwą w osłonie gazów. Omówiono sposoby minimalizacji szkodliwego oddziaływania cynku na jakość połączeń. Przedstawiono jakość, własności i budowę strukturalną połączeń spawanych i lutospawanych blach stalowych.

Słowa kluczowe: blachy stalowe ocynkowane, spawanie stali ocynkowanej, lutospawanie stali ocynkowanej, porowatość, mikrostruktura

\section{Abstract}

Difficulties connected with joining of zinc coated steel components and the influence of zinc on gas metal arc welding and weldbrazing processes have been presented. Minimization methods of zinc harmful effect on quality of joints have been discussed. Quality, properties and structure of welded and weldbrazed joints have been presented.

Keywords: zinc coated steel sheets, welding of zinc coated steel, weldbrazing of zinc coated steel, porosity, microstructure

\section{Wstęp}

Korozja elementów stalowych stanowi ciągle bardzo ważny i istotny problem, który należy brać po uwagę już na etapie projektowania konstrukcji. W praktyce stosowanych jest kilka metod ochrony przed korozją, np.: powłoki ochronne, inhibitory lub ochrona katodowa. Jednym z najczęściej stosowanych rodzajów powłok katodowych jest powłoka na bazie cynku. W różnego rodzaju wyrobach zachodzi często potrzeba łączenia elementów konstrukcyjnych z naniesioną powłoką cynkową. Do łączenia blach z powłokami ochronnymi na bazie cynku można zastosować różne metody łączenia, m.in.: zgrzewanie, spawanie, lutospawanie, a także lutowanie. Spośród procesów łukowych najczęściej stosowane jest spawanie elektrodą topliwą w osłonie gazu aktywnego (MAG) oraz lutospawanie elektrodą topliwą w osłonie gazu obojętnego.

\section{Problemy przy spawaniu elementów stalowych ocynkowanych}

Spawanie metodą MAG elementów ocynkowanych z zastosowaniem drutu litego jest utrudnione ze względu na szczególne właściwości cieplno-fizyczne cynku. Tempe- ratura topnienia cynku wynosi ok. $420^{\circ} \mathrm{C}$, temperatura jego parowania $907{ }^{\circ} \mathrm{C}$, natomiast temperatura topnienia stali to ok. $1480^{\circ} \mathrm{C}$. Ze względu na powyższą różnicę temperatur $\mathrm{w}$ trakcie spawania następuje topienie i parowanie cynku, przez co powstające złącze zostaje pozbawione powłoki ochronnej. Parujący cynk jest z kolei przyczyną porowatości i pęcherzy gazowych w spoinach (rys. 1), a cynk rozpuszczony w stali może prowadzić do powstania pęknięć gorących, usytuowanych w osi spoiny (rys. 2).
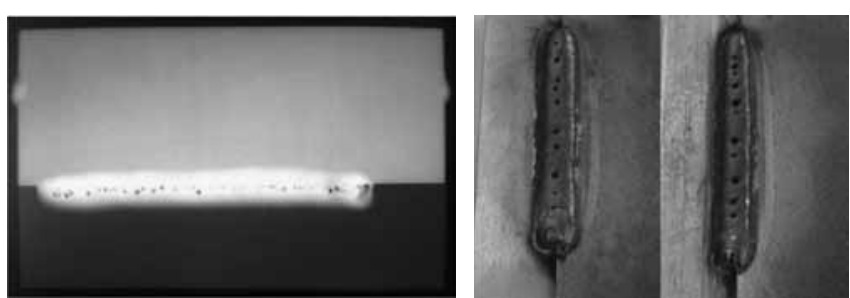

Rys. 1. Radiogram (z lewej) i widok od strony lica (z prawej) złącza zakładkowego blach ze stali ocynkowanej spawanego metodą MAG - widoczna porowatość i pęcherze gazowe

Fig. 1. Radiogram (on the left) and face of a fillet weld (on the right) of a MAG welded overlap joint made of galvanised steel - visible porosity and numerous gas pores

dr inż. Tomasz Pfeifer - Instytut Spawalnictwa, Gliwice. 


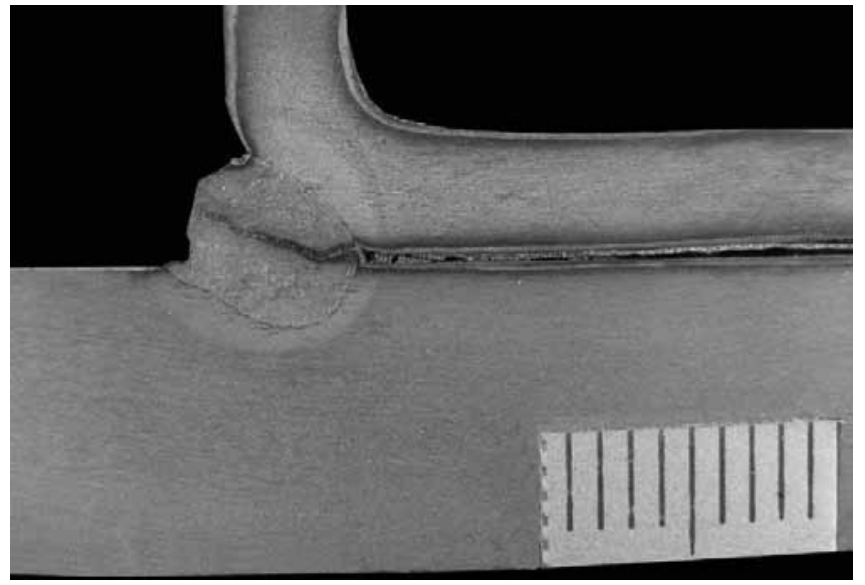

Rys. 2. Makrostruktura połączenia spawanego blachy stalowej z profilem stalowym ocynkowanych ogniowo $z$ widocznym pęknięciem gorącym w spoinie

Fig. 2. Macrostructure of a welded joint connecting a steel sheet with a hot galvanised steel shape; a hot crack visible in the weld

Główną przyczyną tworzenia się pęcherzy gazowych i porów powierzchniowych w przypadku spawania złączy zakładkowych i teowych blach oraz kształtowników ze stali ocynkowanych jest odparowanie dużej ilości cynku i wysoka prężność par tego metalu. W tych warunkach następuje intensywne parowanie cynku z powierzchni łączonych elementów. Powstające pary cynku, nie mając innego ujścia, przechodzą przez ciekłe jeziorko [1 $\div 3]$. Jeśli prędkość krystalizacji jest odpowiednio wysoka (niskie parametry prądowo - napięciowe, duża prędkość spawania) zostają uwięzione w spoinie w postaci pęcherzy kanalikowych i kulistych (rys. 3). W warunkach panujących przy spawaniu blach ocynkowanych, a w szczególności złączy ze spoinami pachwinowymi, ilość par cynku jest bardzo duża, co często powoduje, że jeziorko ciekłego metalu o niewielkich rozmiarach zostaje rozerwane przez uchodzące pary cynku, wskutek czego powstaje porowatość na powierzchni spoiny.

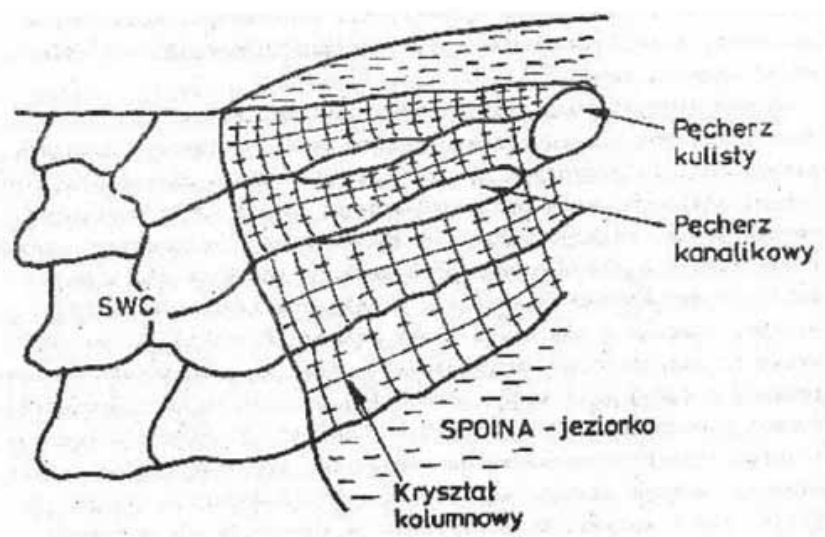

Rys. 3. Przykładowy wygląd pęcherzy kulistych i kanalikowych tworzących się w krzepnącej spoinie [4]

Fig. 3. Exemplary view of globular pores and worm-holes formed in a solidifying weld [4]

Spawanie metodą MAG drutem litym elementów stalowych z powłoką cynkową o dużej grubości $(50 \div 100 \mu \mathrm{m})$, nałożoną ogniowo, może spowodować pęknięcia gorące w osi spoiny, które w znaczący sposób wpływają na obniżenie własności mechanicznych i szczelności połączeń. Niezgodności te pojawiają się $w$ trakcie trwania procesu spawania, a ich przyczyną jest rozpuszczanie się ciekłego cynku w stali oraz niewłaściwe parametry procesu (zbyt duża ilość ciepła powodująca powstawanie nadmiernych naprężeń) [2,3].

Jedną z niezgodności, która zasadniczo obniża este- tykę wykonanego złącza spawanego są odpryski (rys. 4). Odpryski przywierają nie tylko do elementów uchwytu spawalniczego, ale przede wszystkim do spawanego elementu, pogarszając jego estetykę i odporność korozyjną.

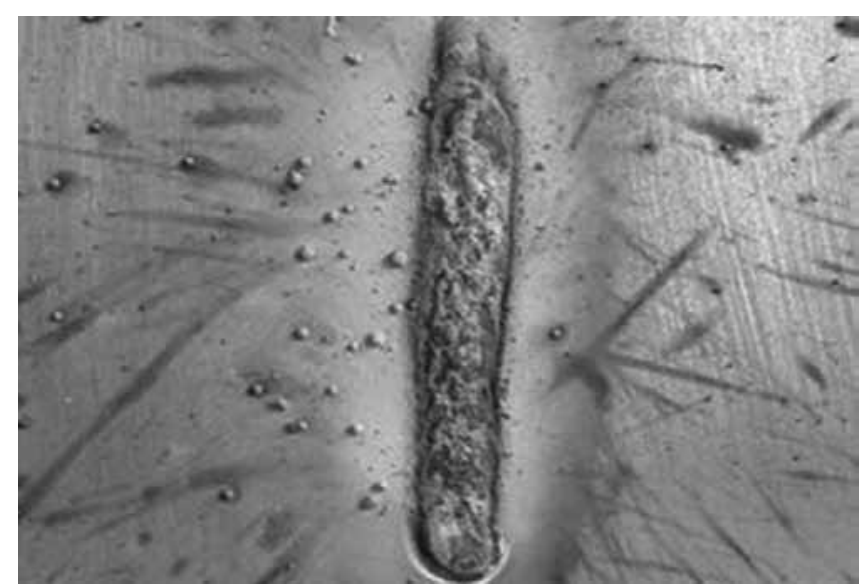

Rys. 4. Widok złącza zakładkowego blach stalowych ocynkowanych (MAG)

Fig. 4. MAG welded overlap weld on a galvanised steel element

Intensywny rozprysk metalu występujący w trakcie spawania, jest następstwem zakłócania zjawiska przenoszenia metalu przez pary cynku. Rozprysk generuje starty materiału dodatkowego na poziomie $5 \div 10 \%$, zmniejsza efektywność i zwiększa koszt prowadzenia prac spawalniczych z uwagi na konieczność czyszczenia lub stosowania preparatów przeciwodpryskowych. Ponadto w trakcie spawania elementów ocynkowanych wydziela się duża ilość toksycznych dymów spawalniczych, które należy skutecznie usunąć ze stanowiska spawalniczego.

\section{Łączenie elementów stalowych ocynkowanych}

Elementy stalowe ocynkowane można łączyć elektrodą topliwą w osłonie gazu stosując procesy spawania i lutospawania drutem litym i proszkowym. Do spawania wykorzystuje się klasyczną metodę MAG oraz jej nowoczesne, niskoenergetyczne odmiany (CMT, ColdArc, STT, AC-Pulse itp.). Spawanie elementów ocynkowanych drutem litym metodą MAG (odmiana klasyczna) wymaga najczęściej usunięcia warstwy cynku z krawędzi oraz z obszaru położonego do ok. $20 \mathrm{~mm}$ od tych krawędzi. Po procesie spawania obszary te należy ponownie zabezpieczyć powłoką cynkową (aerozol, farba, natrysk termiczny itp.). Innym sposobem jest zastosowanie zamiast tego większego odstępu między elementami (spawanie elementów o grubości do $3 \mathrm{~mm}$ bez ukosowania) lub większego kąta ukosowania (do około $75^{\circ}$ ). Zabiegi te pozwalają na łatwiejsze uwalnianie się parującego cynku i zmniejszają skłonność do tworzenia się pęknięć i pęcherzy gazowych. W trakcie spawania elementów ocynkowanych powinno się unikać ruchów zakosowych, które przyczyniają się do wprowadzenia do złącza zbyt dużej ilości ciepła. Podczas spawania należy okresowo kierować łuk spawalniczy przed jeziorko ciekłego metalu, a następnie wracać do niego. Dzięki temu powłoka cynkowa zostaje odparowana jeszcze przed stopieniem krawędzi spawanego elementu. Dobre rezultaty osiąga się stosując wyższe natężenie prądu, dzięki czemu zwiększa się rozmiar jeziorka ciekłego metalu, co umożliwia jego skuteczne odparowanie. Proces spawania zawsze spowoduje odparowanie cynku, dlatego po spawaniu wymagane jest jego uzupełnienie.

Do spawania elementów ocynkowanych metodą MAG (odmiana klasyczna) stosowane mogą być druty proszkowe 
z wypełnieniem metalicznym o oznaczeniu EN ISO 17632-A: T3T Z M M 1 H15 (np. Safdual-ZN firmy Air Liquide lub ClTOFLUX GALVA firmy Oerlikon). Są to druty przeznaczone do spawania w osłonie gazu aktywnego elementów o grubości do $4 \mathrm{~mm}$ jednym ściegiem. Wymagane jest podłączenie drutu elektrodowego do bieguna ujemnego, co zapewnia stabilny przebieg procesu spawania z minimalną ilością odprysków oraz mniejsze wprowadzenie ciepła do materiału. Uszkodzenie powłoki cynkowej jest wtedy najmniejsze, ograniczona jest również skłonność do tworzenia się porów i pęcherzy gazowych. Jednakże druty elektrodowe proszkowe z wypełnieniem metalicznym są kilkukrotnie droższe niż druty lite, wymagają stosowania niskiego napięcia łuku (ok. 11-13 V). Powłoka ochronna cynku w miejscu spawania i od strony przeciwnej ulega uszkodzeniu na mniejszej powierzchni $\mathrm{w}$ porównaniu do spawania drutami litymi, ale obszar ten po spawaniu i tak narażony jest na przyspieszoną korozję i wymaga ponownego zabezpieczenia (rys. 5). a)

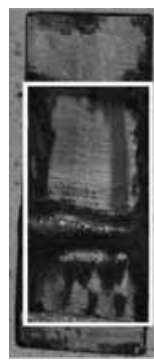

b)

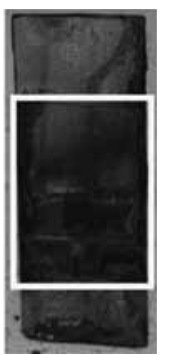

c)

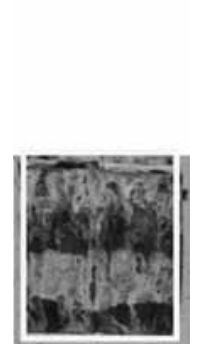

d)

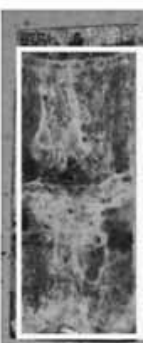

Rys. 5. Stan powierzchni próbek ze złączy spawanych po badaniach korozyjnych a, b - próbki pobrana ze złączy ze stali X2CrNi12 c, d - próbki pobrana ze złączy ze stali E370 ZF 140

Fig. 5. Condition of the surfaces of welded joint specimens after corrosion tests $\mathrm{a}, \mathrm{b}$ - specimen sampled from joints made of $\mathrm{X} 2 \mathrm{Cr}$ Ni12 steel c, d - specimen sampled from joints made of E370 ZF 140 steel

Do spawania elementów stalowych ocynkowanych o grubości w zakresie od 0,5 do $3 \mathrm{~mm}$ można zastosować tzw. niskoenergetyczne odmiany metody MAG, takie jak CMT, ColdArc i STT. Są to modyfikacje spawania łukiem zwarciowym (niskie wartości natężenia prądu i napięcia łuku), w których układ sterowania urządzenia ingeruje w przebieg parametrów prądowo - napięciowych w reakcji na zjawiska zachodzące w łuku elektrycznym oraz w jeziorku ciekłego metalu. Umożliwia to ograniczenie ilości ciepła wprowadzonego do złącza, czego rezultatem jest dobra jakość wykonywanych połączeń i znacznie mniejsze parowanie cynku, a co za tym idzie mniejsze uszkodzenie warstwy antykorozyjnej i wyeliminowanie porowatości $[5,6]$.

Innowacyjnym rozwiązaniem w zakresie niskoenergetycznych odmian spawania metodą MAG jest zastosowanie zmiennej biegunowości w przebiegu prądu spawania i napięcia łuku (AC-Pulse, Cold Process, CMT Advanced). Przeprowadzone w Instytucie Spawalnictwa badania technologiczne wykazały, że proces spawania elektrodą topliwą ze zmienną biegunowością prądu spawania może być stosowany do spawania cienkich blach stalowych (od 0,8 mm do $3 \mathrm{~mm}$ ) z powłokami cynkowymi i cynkowo-żelaznymi, nanoszonymi zarówno w sposób zanurzeniowy jak i galwaniczny. Proces spawania przebiega co prawda mniej stabilnie niż tradycyjne spawanie metodą MAG, natomiast złącza spawane charakteryzują się dobrą jakością i estetyką, są wolne od odprysków. Metoda zapewnienia wymagane warunki spawania (oprócz podstawowych parametrów spawania również możliwość wpływania na ilość wprowadzonego ciepła dzięki regulacji ilości składowej ujemnej), umożliwiając wykonywanie złączy spawanych doczołowych, zakładkowych i teowych blach o grubościach od 0,8 $\mathrm{mm}$ z różnorodnymi powłokami ochronnymi, charakteryzujących się dobrą jakością i dobrymi własnościami mechanicznymi [6:7].

Do łączenia stalowych elementów z powłoką cynkową, zarówno ogniową jak i galwaniczną, z powodzeniem można zastosować lutospawanie elektrodą topliwą w osłonie gazu obojętnego lub aktywnego. Proces ten polega na stapianiu drutu elektrodowego (lut o temperaturze topnienia znacznie niższej niż materiału podstawowego) na materiał łączony, ciepłem łuku spawalniczego, jarzącego się pomiędzy tym drutem a materiałem w osłonie gazu ochronnego. Lutospoina powstaje $\mathrm{w}$ wyniku zwilżenia przez stopione spoiwo powierzchni materiału łączonego podgrzanego ciepłem łuku oraz procesu wzajemnej dyfuzji składników tych materiałów. Materiałem dodatkowym w procesie lutospawania są spoiwa na bazie miedzi. Najpowszechniej stosowane są druty lite i druty proszkowe: CuSi3, CuSi3Mn1Al1.5, CuSi3Mn7. Materiały dodatkowe do lutospawania stali ocynkowanych są znacznie droższe aniżeli druty elektrodowe do spawania tych materiałów.

Jako gaz osłonowy w procesie lutospawania stosowany jest argon (I1 wg PN-EN ISO 14175:2009) oraz następujące mieszanki Ar+ 1 $\div 3 \%$ CO2 (M12 wg PN-EN ISO 14175:2009), a także $\mathrm{Ar}+1 \% 02$ (M13 wg PN-EN ISO 14175:2009). Zastosowanie mieszanek gazowych pozwala na obniżenie napięcia powierzchniowego jeziorka spawalniczego przez co poprawiają się warunki zwilżania i rozpływania stopionego spoiwa na materiale podstawowym. Zwiększa się stabilność łuku i następuje poprawa wyglądu lica spoiny, a także zmniejsza się ilość rozprysków (rys. 6).
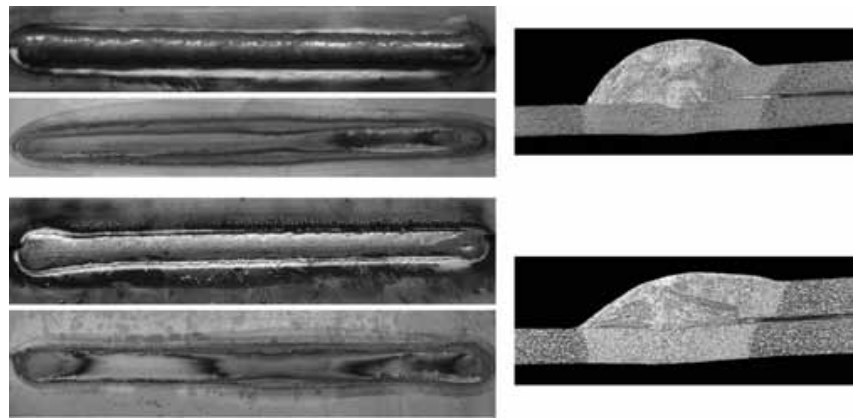

Rys. 6. Wygląd od strony lica i spodu (z lewej) oraz makrostruktury złączy zakładkowych blach ocynkowanej o grubości $1 \mathrm{~mm}$ lutospawanych metodą CMT z użyciem argonu (a) i mieszanki $\mathrm{Ar}+1 \% \mathrm{O}_{2}$ (b) jako gazu osłonowego [5]

Fig. 6. View from the face and root side (on the left) and macrostructure of overlap joints made of zinc coated steel (thickness 1,0 $\mathrm{mm}$ ) during CMT weldbrazing using argon (a) and $\mathrm{Ar}+1 \% \mathrm{O}_{2}$ mixture (b) as shielding gas [5]

Należy zaznaczyć, iż lutospawanie MIG/MAG elementów stali ocynkowanych z zastosowaniem spoiw miedzianych pozwala na uzyskanie złączy cechujących się wysoką estetyką lutospoiny i korzystną geometrią, zarówno lica jak i grani.

Lutospawanie prowadzone jest prądem stałym, pulsującym lub prądem o zmiennej biegunowości. Stosowane są również niskoenergetyczne odmiany spawania elektrodą topliwą, takie jak CMT i ColdArc. Nowoczesne odmiany lutospawania elektrodą topliwą pozwalają uzyskać drobnokroplowe przechodzenie materiału elektrody do jeziorka. Taki sposób prowadzenia procesu pozwala na ograniczenie ilości wprowadzonego ciepła i zmniejsza odparowanie warstewki ochronnej, pozwala również na łączenie bardzo cienkich elementów przy minimalnym ich odkształceniu, a jednocześnie większej wydajności procesu. 
Zastosowanie prądu o zmiennej biegunowości do lutospawania blach ocynkowanych, umożliwia uzyskanie złączy cechujących się bardzo dobrą jakością, a rozpływność ciekłego lutu w porównaniu do lutospawania prądem stałym jest znacznie większa (rys.7).
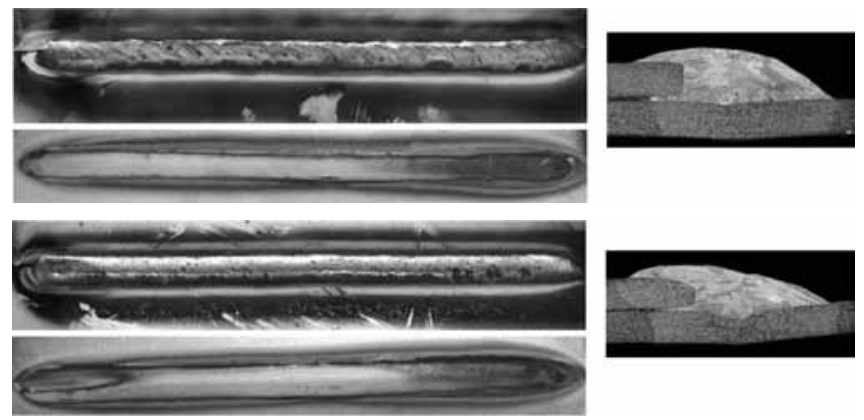

Rys. 7. Wygląd od strony lica i spodu (z lewej) oraz makrostruktury złączy zakładkowych blach ocynkowanej o grubości $1 \mathrm{~mm}$ lutospawanych metodą AC-Pulse z użyciem argonu (a) i mieszanki $\mathrm{Ar}+1 \% \mathrm{O}_{2}$ (b) jako gazu osłonowego [8]

Fig. 7. View from the face and root side (on the left) and macrostructure of overlap joints made of zinc coated steel (thickness 1,0 mm) during AC-Pulse weldbrazing using argon (a) and $\mathrm{Ar}+1 \% \mathrm{O}_{2}$ mixture (b) as shielding gas [8]

Lutospawanie może również być stosowane do wykonywania złączy doczołowych elementów stalowych ocynkowanych. Złącza charakteryzują się bardzo dobrą jakością (rys. 8), a badania wytrzymałości na rozciąganie elementów wykonanych ze stali 800DP z powłoką cynkową wykazały, że wytrzymałość statyczna na rozciąganie wynosi ok. $500 \mathrm{MPa}$.
Wysoka wytrzymałość wynika z wymieszania materiału podstawowego ze stopiwem drutu elektrodowego oraz z utworzenia się faz międzymetalicznych bogatych w żelazo i miedź . Złożoną strukturę lutospoiny w pobliżu granicy materiał podstawowy - stopiwo przedstawiono na rysunku 9.

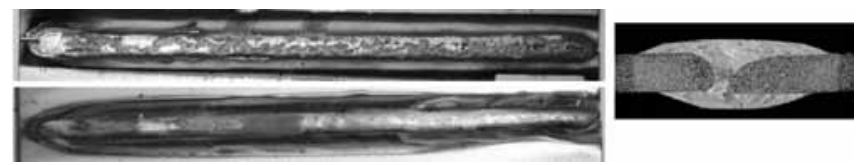

Rys. 8. Wygląd od strony lica i spodu (z lewej) oraz makrostruktura złącza doczołowego blach ze stali 800DP o grubości $1 \mathrm{~mm}$ ocynkowanej galwanicznie lutospawanego metodą AC-Pulse z użyciem argonu jako gazu osłonowego [9]

Fig. 8. View from the face and root side (on the left) and macrostructure of butt joint made of 800DP galvanized steel sheets (thickness $1,0 \mathrm{~mm}$ ) during AC-Pulse weldbrazing using argon as shielding gas [9]

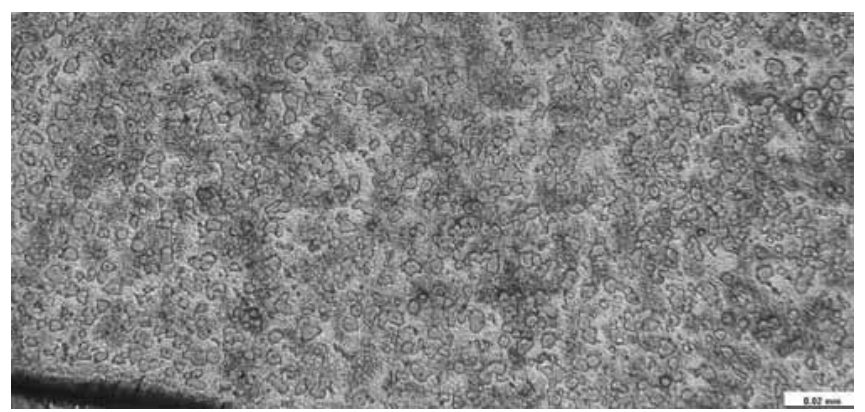

Rys. 9. Mikrostruktura lutospoiny w pobliżu granicy rozdziału, traw. $\mathrm{FeCl}_{3}$, pow. $500 \mathrm{x}$

Fig. 9. Microstructure of brazeweld in the vicinity of phase boundary, etch. $\mathrm{FeCl}_{3}$, magnification 500x

\section{Wnioski}

Technologia spawania metodą MAG elementów stalowych ocynkowanych powinna być starannie opracowana i powinna uwzględniać właściwości fizykochemiczne powłoki cynkowej.

Zastosowanie procesu lutospawania prądem ze zmienną biegunowością z wykorzystaniem drutu elektrodowego litego CuSi3Mn1 oraz argonu i mieszaniny $\mathrm{Ar}+1 \% \mathrm{O}_{2}$ zapewnia uzyskanie połączeń charakteryzujących się bardzo dobrą jakością i estetyką.

Złącza doczołowe lutospawane prądem o zmiennej biegunowości charakteryzują się bardzo wysoką wytrzymałością na rozciąganie (nawet ok. $500 \mathrm{MPa}$ ), wynikającą z budowy strukturalnej połączenia.

\section{Literatura}

[1] Grundmann J.: Jakość, wydajność i wynikające stąd koszty spawania stali węglowych w osłonie gazów aktywnych, Biuletyn Instytutu Spawalnictwa $\mathrm{nr} 5 / 2005$.

[2] Ambroziak A.: Wpływ technologii spawania na grubość powłoki na złączu po cynkowaniu ogniowym, Przegląd Spawalnictwa nr 8-10/2002

[3] Wilden J., Bergmann J.P.: Łączenie stali ocynkowanej - stan aktualny i perspektywy, Przegląd Spawalnictwa nr 8-9/2004.

[4] Węgrzyn J.: Fizyka i metalurgia spawania, Wydawnictwo Politechniki Śląskiej, 1990.

[5] Matusiak J., Czwórnóg B., Pfeifer T.: Spawanie i lutospawanie niskoenergetycznymi metodami MIG/MAG przeznaczonymi do łączenia materiałów i elementów wrażliwych na ciepło, Biuletyn Instytutu Spawalnictwa $\mathrm{nr} 6 / 2007$.

[6] Matusiak J., Pfeifer T., Wyciślik J., Kiszka A.: Badanie wpływu warunków technologicznych i materiałowych na emisję pyłu i gazów przy spawaniu metodą Cold Process i AC MIG PULSE blach stalowych z nowoczesnymi powłokami ochronnymi, Praca badawcza IS Ma $34 / 2011$.
[7] Pfeifer T., Kiszka A.: Spawanie cienkich blach stalowych z powłokami ochronnymi metodą MAG prądem o zmiennej biegunowości, Biuletyn Instytutu Spawalnictwa nr 2/2012.

[8] Pikuła J., Pfeifer T., Mendakiewicz J.: Wpływ gazu osłonowego na własności połączeń blach ocynkowanych wykonanych metodą lutospawania MIG/MAG prądem o zmiennej biegunowości, Biuletyn Instytutu Spawalnictwa $\mathrm{nr} 1 / 2014$.

[9] Pfeifer T., Winiowski A., Majewski D., Rykała J.: Badania wpływu warunków lutospawania łukowego elektrodą topliwą prądem o zmiennej biegunowości blach ocynkowanych na jakość i własności użytkowe połączeń, Praca badawcza IS Cc-56/2013.

[10] Różański M., Gawrysiuk W.: Lutospawanie MIG/MAG blach ocynkowanych i przykłady trudno spawalnych układów materiałowych, Przegląd Spawalnictwa nr 9/2007. 